\title{
BY ANOTHER WAY OF DECEPTION: THE USE OF CONSPIRACY THEORIES AS A FOREIGN POLICY TOOL IN THE ARSENAL OF THE HYBRID WARFARE
}

\author{
Dr. Kiril AVRAMOV
}

\begin{abstract}
This article provides analysis of the spread, specifics, usage and 'mechanics' of proliferation of the so-called 'conspiracy theories' - an informational aspect of the hybrid warfare - as an offensive disinformation dissemination weapon for pressuring political decision-makers in selected countries at critical junctures.
\end{abstract}

Keywords: hybrid threats, deception, conspiracy theories, foreign policy.

\section{Introduction}

When analysing the use of information as an offensive weapon that helps the current Kremlin's administration to reach its meta foreign policy goals and overcome its relative international isolation, we should be aware of the varied arsenal of techniques that range from targeted planting of disinformation in foreign media to fostering steady supply of "alternative histories" and outright both ontologically false and effective conspiracy theories in the Russian mainstream media and social networks via its "mighty internet troll army"1 that later are picked up and endlessly duplicated and hybridized across various conventional and non-conventional media outlets throughout Central, Eastern Europe and especially in the "periphery" of the EU. All these methods and instruments bear the hallmark of "weaponization of information, culture and money" approach that departs radically from the so-called soft power strategy. It should be noted that this approach and its respective policy tool-kit inherits the best of the Soviet-style "active measures" psy-ops instrumentation, and specifically, the "dezinformatziya" measures that have proven to be so successful during the Cold War era. In this paper I will argue that the intensity ${ }^{3,4}$ in the past several years of the distribution of permanent targeted disinformation in the form of conspiracy theories led by diversified sources ${ }^{5}$ has increased and represents an important informational aspect of the hybrid warfare, as an offensive disinformation dissemination strategy for 
pressuring governments, political decision-makers, civic organizations and even individuals in selected countries at critical junctures that deserve innovative, intensive, collective and coordinated deterrence strategic approach in terms of countering its degrading effects on national security.

\section{Context}

In their recent book titled "Eurasian Disunion: Russia's Vulnerable Flanks" Janusz Bugajski and Margarita Assenova present an overview of foreign policy objectives, strategies and tactics, methods, opportunism and capabilities of Putin's administration. Notable part of this seminal work is dedicated to the arsenal of subversive tools used to implement the Russian foreign policy goals outside its borders. These in turn are grouped into eight main clusters, "namely international, informational, ideological, economic, ethnic, political, social, and military" that utilize no less than sixty different weapons to block and subvert Russia's adversaries. ${ }^{7}$ Special attention is drawn to the so-called information / propaganda war that is used as a tool in the wider arsenal of the so-called "hybrid warfare" for gaining support of one side and undermining the trust and legitimacy of the adversaries of the Russian foreign policy under Putin. This particular work and scores of other scholarly articles and recent studies point out that information warfare of this particular kind is very efficient and, compared to other tools, a cheaper method for "reconquering the hearts and minds" of targeted audiences in former countries that used to belong to the former socialist camp. It comes in various forms and shapes, i.e. "selected segmentation" and accent of news, propaganda clichés, manipulation of fears of the targeted audiences and proliferation, duplication and "hybridization" of conspiracy theories.

As noted correctly in Ben Nimmo's analysis of the informational war waged by contemporary Russia, ${ }^{8}$ when it comes to defence of Russian stance, then we witness the so-called 4-D method (i.e. dismiss, distort, distract, dismay), but when we consider the Russian narratives as an offensive weapon then everything is allowed and possible, including the heavy use of conspiracy theories aimed against governments, parties, movements, cultural and subcultural milieus all the way down to specific targeted individuals who represent "an obstacle" to Kremlin's foreign policy goals. When speaking about those goals we should bear in mind the notable observation of Stephen Holmes and Ivan Krastev ${ }^{9}$ that, unlike the Soviet Union, today's Putin's Russia has no grand ideological alternative to propose and advance on the world stage; in fact, it has no grand strategy at all. In other words, it is all about tactics and survival. Thus, it merely acts offensively to repel the next incoming crisis. It is precisely due to the "lack of vision for the future that Russian elites are tempted by conspiracy theories and apocalyptic pronouncements." 10 In addition, it should be noted that Putin's Kremlin is incredibly paranoid and conducts its own "paranoid style" 11 of politics 
within and outside Russia's borders that drives the ruling elites to produce and promote seemingly endless stream of conspiracy theories for internal and external consumption. This stream in turn is channelled by offensive tactics.

\section{Information as an Offensive Weapon}

The use of information as an offensive weapon in the arsenal of foreign policy and as a part of a wider hybrid warfare tactics and strategies is marked by its incredible flexibility, potency and resilience when operating in targeted countries. Regardless of the variety and combination of uses, the main utility function of this weapon is to reach its intended aim. This aim could be broadly described as the distortion of the cognitive evaluation of the targeted audiences in the selected targeted countries in order to persuade them to either support or oppose selected policies pursued by third interested parties and reaching their meta foreign policy goals. In other words, this weapon in this particular case is used to "recapture the hearts and the minds" of pre-selected audiences targeted by Kremlin's administration to persuade them to support or reject certain domestic policies or block international initiatives that are not up to the taste of the Russian Federation's leadership. Usually, these targeted audiences could be broadly described as the social segments that are the "losers of transition" on the dual track to democracy and market economy that harbour mostly negative sentiment towards the new post-socialist status quo and tend to support heavily ultra-nationalist and populist political sentiments. It is also used to pressure the governments of the ex-socialist countries, key political decision-makers, active civic organizations and even influential individuals in selected countries at critical junctures when it comes to the implementation of policies that are seen as detrimental to the current Russian interests.

The "new" battlefield in this struggle to regain the support of the targeted and segmented Eastern European societies tends to be the good old public discourse that is led in all forms of communication ranging from traditional to so-called "new" media. Having in mind the opaque structure of media ownership, non-transparent financing of informational outlets, coupled with plummeting media freedom and auto censorship, the use of information as an offensive weapon can be particularly relevant and effective. Simple numerical variety and availability of media sources in Eastern and Central European countries amplified by social media in addition to low quality of journalism do not guarantee the level of objectivity and do not foster environment of critical evaluation of complex issues. They also do not guarantee any "objectivity" of the information flow that is presented to the wider public. Such environment literally invites for heavy use of disinformation campaigns, sensationalism and encouragement of proliferation of false information coverage that in turn aims to create cyclical panics and public hysteria. Notable parts of these campaigns are the spread and satura- 
tion with conspiracy theories. These are designed to affect heavily the targeted audience in the respective countries, as the targeted audiences are not competent to evaluate and critically judge the information pertaining to every important policy topic in order to form their own opinion.

\section{Conspiracy Theories - Powerful Instrument in the Information Warfare Arsenal}

The range of offensive warfare techniques is incredibly diverse and complex, and covers ground anywhere from targeted planting of disinformation in foreign media to fostering steady supply of "alternative histories" of the totalitarian past of the targeted countries and outright both ontologically false and effective conspiracy theories ${ }^{12}$ (i.e. where false conspiracy theories are the ones that represent a radical departure from reality, whereas the effective conspiracy theories are the ones deemed to be socalled "half-truths" - mixture of facts and lies and removal of context). The use of conspiracy theories however is not a new phenomenon at all - they were employed by the then Soviet foreign policy and represent the best of the Soviet-style "active measures" psychologic operations instrumentation and specifically the so-called "dezinformatziya" measures that have proven to be so successful during the Cold War era. If we can state that the proliferation and usage of conspiracy theories as an offensive information weapon are not an uncommon phenomenon at all, then it is necessary to point out that the novelty in their exploitation against targeted Eastern and Central European audiences we are witnessing is in the "fusion effect" of the combination of "the weaponization" of distorted information and finance penetration in the region. All of this represents a radical departure from the so-called "soft power" 13 approach to influence and foreign policy.

Conspiracy theories spread, duplication and planting are not a new phenomenon either and there are countless examples from both sides of former "Iron curtain" and well-before that to support that claim when it comes to issues connected to national identity formation, political regime consolidation, populism "waves," etc. Despite the lack of novelty here, research attention should be applied to this phenomenon in recent years due to several distinct reasons, namely (1) general "spike" of proliferation and circulation of conspiracy theories in ex-socialist media outlets; (2) the spread of the conspiratorial mind-set is much wider than expected, i.e. conspiratorial thinking mode is not a marginal but a mainstream phenomenon; ${ }^{14}$ and (3) the possibility of a strong link between the general rise of populism and the spike of circulation of conspiracy theories. It should be noted that their importance is tied to the end-goals their purveyors have in mind.

These include the attempts to affect personal and group values formation, cognition mapping and decision making, as well as the orchestrated efforts to apply public pres- 
sure from within to modify key decisions, policies and public opinion at large in favour of Kremlin's foreign policies and their objectives. Speaking of these, they could be grouped into several meta-categories, namely (1) overarching goal of Putin's administration to promote and press for a "multipolar world order" as a direct challenge towards the perceived US global hegemony; (2) juxtaposing Kremlin as an unavoidable factor on the stage of international relations' and (3) advancement and fortification of its already entrenched political, economic and cultural interests in its former sphere of influence.

\section{Anatomy of Conspiracy Theories}

When discussing the issue of conspiracy theories as a foreign policy tool in the arsenal of the hybrid warfare we should be mindful of their "anatomy" and functionality. Conspiracy theories traditionally are viewed as "marginal phenomena" that threaten the mainstream political consensus ${ }^{15}$ - in other words, sort of a "glitch" in the system of democratic governance. However, newer approaches to analysing the phenomenon point out that conspiracy theories and the mindset associated with them might not be as marginal, as thought of previously. Suggestion in that direction could be found in the works of Fenster, ${ }^{16}$ Yablokov, ${ }^{17}$ and possibly Parish. ${ }^{18}$ All of these works point out that conspiracy theories serve multiple explanatory functions, such as "populist theory of power," device for coping with the anxieties of the age of globalization and method of approaching the complex issues of modern inequalities, and not only a "poor man's cognitive map" to the post-industrial age. All of these claims do hold quite good explanatory power pertaining to the functions of the conspiracy theories beyond a "marginal glitch," however the one that seems most relevant in their use as an information weapon seems to be the idea of analysing conspiracies as a populist tradition regarding power. One explanation however stands out, namely where the theory constitutes two distinct entities - "the people" that are pitched against the ultimate "Other", where the "Other" is a "secretive power bloc." Thus, in the field of political arena the "pure people" are constantly battling "the power bloc" that is conspiring on them. Thus, the conspiracy theories are a kind of "glue" for social cohesion of the "people" that unite to oppose the secretive power and its plots but also as a narrative modality that deals with the unequal access to capital and political power.

When these concepts are applied in the context of Eastern and Central Europe and the countries belonging to the former sphere of influence of the USSR, then we can observe that conspiracy theories are used as an information weapon usually by authoritarian regimes as a tool for uniting targeted audiences against the imaginary "Other." Today the Russian Federation is the ultimate leader in the process of production and distribution of conspiracy theories at home and abroad, and utilize them as a defensive shield for Kremlin to "filter out" alternative information streams within the Rus- 
sian Federation to protect the current regime. Simultaneously, in terms of "export" we are witnessing a large-scale coordinated operation by a kind of "Ministry of Truth" aided by the state and backed by a nexus of outlets such as RT (former Russia Today), Sputnik, and augmented by a large internet "troll army" that literally "flush" the targeted audiences on a daily basis with sensational conspiracies that "explain" the events from Moscow to Aleppo and from Washington through Brussels to Beijing. The political utility function that these theories serve is to explain and justify the Russian nationalist and neo-imperialist project worldview where the West in general is portrayed as the "insidious Other" that is undermining the Russian progress on a global scale. In addition, they serve as illustrative examples of the "unjust" foreign policy alliances of the West against the global underdog (i.e. the Russian Federation) that deserves support and understanding being the sole defender of the "traditional" values that are being attacked by the Western liberal forces aiming to degrade the very foundations of the Russian state.

In essence, the conspiracy theories in Kremlin's arsenal not only seek to persuade anti-liberal audiences in the former socialist countries but to reach out to previously pro-Western constituencies, as well. The accent of this approach is to highlight and magnify the "blunders" of the West and the fallacies towards the people of Eastern and Central Europe pertaining to meaningful provision of a long-term alternative within the "structures of the West" (EU and NATO for instance). Interestingly enough, this "export" approach relies on conspiracy theories that are either originally American and which are directed against the US and the West in general or AntiRussian. These in turn are presented as purely populist "alternative explanatory world-view" directed at the segments of the general publics in Central and Eastern Europe who are disillusioned with the results of transformations and transitions. In sum, when observing the anatomy of conspiracy theories, we can safely state that (1) conspiracy theories are a potent tool for public diplomacy, (2) conspiracy theories are an efficient weapon for alternative influence, and (3) conspiracy theories are a frequently used instrument for creating cyclical public panics and hysterias. These in turn are directed towards all active local civic groups, organizations and minority groups (ethnic, religious, sexual, etc.) that publicly have expressed consistent position against the "status quo" (i.e. against state capture and corruption aided by the local elites' shady deals with Russian oligarchy) and lack of reforms in the respective countries.

\section{Key Themes and Narrative Matrixes}

When dealing with the key themes and narrative matrixes of the conspiracy theories in circulation that are spread by sensationalist Eastern European media with Russian direct or indirect financial, logistical or ideological support we should attempt an ef- 
fort towards differentiation of these "explanations," in order to distinguish them better for the sake of comparison and genesis. Thus, we can differentiate the narrative matrixes and their key themes in terms of origin. In this regard, we can distinguish at least three types of conspiracy theories in circulation, namely: (1) original local conspiracies; (2) non-original - imported, carbon-copied; and (3) hybrid - non-original flavoured with "local twist." Original local conspiracy theories are usually the ones that do not mimic or carbon-copy already existing theories that circulate mainly in the West. Such one for instance, in the case of Bulgaria would be the so-called "RahnUtt" "secret American plan for reduction of the Bulgarian population via introducing market economy measures" that would produce deliberate economic and social shocks. Such local conspiracy theory with its multiple variations is one of the all-time favourites of Bulgarian populists and ultra-nationalists. Non-original samples to illustrate the second type of conspiracy theories in circulation are the alleged plots from the "enemies from outside and above" of the "pure nation," such as the World Jewry, Illuminati, New World Order (NWO), International bankers and "Sorosoids" (i.e. paid agents of George Soros) plots that are copied from persisting age-old conspiracy theories that were initially designed and spread outside Russia and Eastern Europe. The hybrid type is quite an interesting one as it incorporates local elements into already existing myths, thus making the conspiracies more suitable and relevant for local consumption.

Inevitably, all of the most of the sampled popular conspiracy theories and their multiple variations in circulation in Bulgaria and other Eastern European states do feature one or more "deconstructive" narrative matrixes that are aimed to "reveal" the "hidden nature" of these respective countries' strategic choices to belong to common European or Euro-Atlantic structures (i.e. outside the Russian sphere of influence). These include: (1) European unity within the structures of the EU is doomed, as the Union is corrupt, lax, decadent and weak; (2) EU is a failed experiment based on multiculturalism; (3) liberal democracies are weak, incapable of defending themselves, thus doomed to fail; (4) EU is a giant on a clay feet, as it does not have the military might of other superpowers; (5) Brussels-based elites are stooges for the ones in Washington, thus incapable of forming independent policies; (6) the participation of the former countries of the Eastern Block in the EU is to their ultimate detriment economies do not converge with the West and these countries are bound to be consumed soon by the Washington-inspired "Islamic conquest" of Europe; (7) US is looking to pitch "the new democracies" of Europe against older EU members in order to undermine EU's unity, as the ultimate American goal is to eliminate EU as a global competitor; (8) NATO is the real "exporter of instability" as it deliberately threatens Russia and destabilizes Europe and does not really provide for the security of its members; and (9) the real victim of the aggressive American and mostly "Anglo- 
Saxon" foreign policies is Russia, as it is "besieged" by proxies that look for its territorial dismemberment, humiliation, alienation and ultimate defeat.

It should be noted that the sample of the matrixes reveal overlap and "interlocking" that suggest the seeking of the "super conspiracies"19 effect where the complex conspiracy worldview is encouraged and seemingly unrelated. Conspiracy narratives actually are interconnected to "reveal" the "hidden reality" and true "agenda" of the omnipotent manipulators. In this regard, the effort of the Russian disinformation and propaganda is to paint the efforts of Kremlin to defend, contest and oppose the West in any form, as an epic struggle between ultimate good and evil in global proportions with mythical significance that has no less than the future of civilizations at stake. This mythic struggle requires that publics should take sides and make binary "moral" choices, as such reality cannot tolerate passive or indecisive stance.

These narrative matrixes and their variations do clearly indicate the main directions of the Russian disinformation efforts, their respective targets and projected aims to achieve - planting general mistrust regarding the European Union and NATO countries member cohesion, capabilities and effective internal and foreign policies among the targeted Eastern and Central European publics. It should be added that such conspiratorial narratives draw their potency on their emotional appeal towards the abovementioned strata deemed to be "losers from transitions" in former socialist countries. Such appeal targets to invoke and strengthen the already existing "socialist nostalgia" and to provoke moral panics and mass hysterias that are able to block rational decision-making on political level, encourage rise of anti-systemic political and social actors and obstruct efforts to neutralize Russia-backed propaganda and disinformation within these societies.

\section{Conclusion}

In conclusion of this short overview dedicated to the topic of conspiracy theories and their use as foreign policy tools in the arsenal of hybrid warfare we can highlight several important tendencies and features. These include the observation that the "age of anxiety" is firmly present in Russia and post-socialist Eastern and Central Europe and there are multiple publics that eagerly produce and consume conspiracy theories. Also, we are witnessing a growing proportion of publics on the demand side that partake into proliferation of complex conspiracy theories, thus making the phenomena of conspiracies mainstream and not marginal in Eastern and Central European societies today. Having in mind this wide spread of conspiratorial mindset in the region, it should be only logical to acknowledge that conspiracy theories represent a fairly powerful offensive instrumentation when used as a foreign policy tool by third interested parties, in this case the Russian Federation's administration. Conspiracy theories are highly appealing on emotional level, as they seek to provoke powerful feel- 
ings connected to sense of security, identity and overall sense of purpose and direction. Thus, they become potent instruments to polarize and divide targeted publics making them very prone to intended "alternative influence." As corruption, lack of transparency in political decision-making coupled with sclerotic responses from national and transnational elites to pressing issues regarding national security, social wellbeing and identity continue to mar the discourse of the national political debates, conspiracy theories gain ground, as a reaction to inadequate responses on the side of the elites. As the elites create informational "vacuum," conspiracies readily fill it in.

It is certain that this situation needs to be addressed at the European Union and NATO, as well as member countries' national governments level in a most coherent manner, for the wider and deeper the spread of disinformation, the larger the chance of undermining the strategic geopolitical consensus of respective countries. It should be noted that such responses are visible at EU level, where the External Action Service of the Union has created its East StratCom Task Force in March of 2015 to deal with Russia's ongoing disinformation campaigns. The method of EEAS' East StratCom Task Force relies on debunking conspiracy theories via publishing a thorough analysis in its weekly newsletters "Disinformation Digest" and "Disinformation Review" compiled with the help of professional staff aided by a wide network of national contributors and fact-checkers. Their working method of exposure and debunking seems to fall in line with the findings of some of the latest empirical data ${ }^{20}$ on the subject suggesting that provision of rational argumentation, as opposed to ridiculing and empathy, remains one of the efficient ways to counter the disinformation via conspiracy theories. However, such coordinated and methodologically sound effort is not always observed at national governments level, especially when dealing with heavily targeted countries, both EU and NATO members, as Bulgaria is. Also, notable is the lack of will to address the issue on the part of certain national governments and administrations, despite the ample evidence of Russian disinformation activities in these targeted countries. Last but not least, much remains to be desired from the other targeted institution, namely NATO, in addressing and dealing with conspiracy theories that are actively used as foreign policy tools for "alternative influence" in its member countries on behalf of the Russian Federation.

\section{Notes}

${ }^{1}$ Virginia Harrison and Alla Eshchenko, "Inside Russia's Pro-Putin Troll Factory," CNN, 3 September 2015, http://money.cnn.com/2015/09/03/news/russia-troll-factory-putin/, accessed May 11, 2018.

${ }^{2}$ Peter Pomerantzev and Michael Weiss, "The Menace of Unreality: How the Kremlin Weaponizes Information, Culture and Money," The Institute of Modern Russia, 2014, accessed October 15, 2015, http://www.interpretermag.com/wp-content/uploads/2014/ 11/The_Menace_of_Unreality_Final.pdf. 
${ }^{3}$ Intelligence Services of the Czech Republic's (BIS), "Annual Report of the Security Information Service for 2014," Section 2.3, 2015, http://www.bis.cz/vyrocnizpravaEN6c8d.html?ArticleID=1096\#_Toc115828878.

${ }^{4}$ Bulgarian Ministry of Defence (MOD)'s, "Annual Report about the State of Defence and the Armed Forces for 2014," Section 2.1, Sofia, March 2015, http://www.md.government.bg/ bg/doc/drugi/20150327_Doklad_MO_2014.pdf.

5 Il'ja Jablokov, "Enemies, Traitors, Fifth Columns Russian Conspiracy Theories on the Ukraine Crisis," Osteuropa 65, no. 4 (2015): 99-+.

${ }^{6}$ Janusz Bugajski and Margarita Assenova, Eurasian Disunion: Russia's Vulnerable Flanks, (Washington, D.C.: The Jamestown Foundation, 2016).

7 Janusz Bugajski, "Russian Foreign Policy under Putin," Journal Diplomacy, Diplomatic Institute of MFA of Bulgaria, no. 14 (May/September 2015): 43-48.

${ }^{8}$ Ben Nimmo, "Anatomy of an Info-war: How Russia's Propaganda Machine Works, and How to Counter It," Central European Policy Institute, 2015, https://www.stopfake.org/en/ anatomy-of-an-info-war-how-russia-s-propaganda-machine-works-and-how-to-counter-it/, accessed May 16, 2018.

9 Stephen Holmes and Ivan Krastev, "The Weakest Strongman," The New Republic magazine, January 11, 2012, http://www.newrepublic.com/article/world/magazine/99527/strongmanputin-march-kremlin, accessed May 16, 2018.

${ }^{10}$ Ivan Krastev, "What the West Gets Wrong about Russia," New York Times, 12 August 2015, https://www.nytimes.com/2015/08/13/opinion/what-the-west-gets-wrong-about-russia.html, accessed May 16, 2018.

${ }^{11}$ Richard Hofstadter, "The Paranoid Style in American Politics," Harper's Magazine (November 1964): 77-86.

${ }^{12}$ Kiril Avramov, "The Putin Administration's Use of 'Conspiracy Theories' against Former Communist States. The Case of Bulgaria," Southeastern Europe, Brill, under review.

${ }^{13}$ Joseph S. Nye, Jr., Bound to Lead: The Changing Nature of American Power (New York: Basic Books, 1990).

${ }^{14}$ Ilya Yablokov, "Conspiracy Theories as a Russian Public Diplomacy Tool: The Case of Russia Today (RT)," Politics 35, no. 3-4 (2015): 301-315, https://doi.org/10.1111/14679256.12097.

${ }^{15}$ Hofstadter, "The Paranoid Style in American Politics."

${ }^{16}$ Mark Fenster, Conspiracy Theories: Secrecy and Power in American Culture, (Minneapolis, MN: University of Minnesota Press, 2008).

${ }^{17}$ Ilya Yablokov, "Pussy Riot as Agent Provocateur: Conspiracy Theories and the Media Construction of Nation in Putin's Russia," Nationalities Papers 42, no. 4 (2014): 622-636.

${ }^{18}$ Jane Parish, "The Age of Anxiety," The Sociological Review 48, no. S2 (2000): 1-16.

${ }^{19}$ Michael Barkun, Culture of Conspiracy: Apocalyptic Visions in Contemporary America, (Berkeley, CA: University of California Press, 2013).

${ }^{20}$ Gábor Orosz, Péter Krekó, Benedek Paskuj, István Tóth-Király, Beáta Bőthe, and Christine Doris Roland-Levy, "Changing Conspiracy Beliefs through Rationality and Ridiculing," Frontiers in Psychology 7 (2016), Article 1525, https://doi.org/10.3389/fpsyg.2016.01525. 


\section{About the author}

Dr. Kiril Avramov is Assistant Professor of Political Science at the Department of Political Science at the New Bulgarian University, Sofia, Bulgaria. He is former Fulbright Visiting Fellow at the Center for Russian, East European and Eurasian Studies (CREEES) at the University of Texas at Austin, United States.

E-mail:k.avramov@nbu.bg, kiril.avramov@nbu.bg. 